\title{
Provitamin A carotenoids are independently associated with matrix metalloproteinase-9 in plasma samples from a general population.
}

\author{
Mireille Rydén, Peter Garvin, Margareta Kristenson, Per Leanderson, \\ Jan Ernerudh and Lena Jonasson
}

\section{Linköping University Post Print}

N.B.: When citing this work, cite the original article.

This is the authors' version of the following article:

Mireille Rydén, Peter Garvin, Margareta Kristenson, Per Leanderson, Jan Ernerudh and Lena Jonasson, Provitamin A carotenoids are independently associated with matrix metalloproteinase-9 in plasma samples from a general population., 2012, Journal of Internal Medicine.

which has been published in final form at:

http://dx.doi.org/10.1111/j.1365-2796.2012.2534x.x

Copyright: Blackwell Publishing

http://www.blackwellpublishing.com/

Postprint available at: Linköping University Electronic Press

http://urn.kb.se/resolve?urn=urn:nbn:se:liu:diva-75982 
Provitamin A carotenoids are independently associated with matrix metalloproteinase-9 in plasma samples from a general population

Short title: Carotenoids are inversely related to MMP-9 in plasma

Mireille Rydén ${ }^{1,2}$, Peter Garvin ${ }^{3,4}$, Margareta Kristenson ${ }^{3}$, Per Leanderson ${ }^{5}$, Jan Ernerudh ${ }^{6}$, Lena Jonasson $^{1}$

${ }^{1}$ Division of Cardiovascular Medicine, Department of Medical and Health Sciences, Linköping University, Sweden

${ }^{2}$ Department of Cardiology, Örebro University Hospital, Örebro, Sweden

${ }^{3}$ Division of Community Medicine, Department of Medical and Health Sciences, Linköping

University, Linköping, Sweden

${ }^{4}$ Psychobiological Determinants of Health Laboratory, Department of Psychology, University of British Colombia, Vancouver, Canada

${ }^{5}$ Division of Occupational and Environmental Medicine, Department of Clinical and Experimental Medicine, Linköping University, Linköping, Sweden

${ }^{6}$ Clinical Immunology, Department of Clinical and Experimental Medicine, Linköping University and Department of Clinical Immunology and Transfusion Medicine, County Council of Östergötland, Sweden

Keywords: carotenoids, diet, inflammation, matrix metalloproteinase, provitamin A. 
Abstract

Background and aim: Carotenoids in plasma are inversely associated with cardiovascular risk. Low levels can be explained by low dietary intake but also by a number of other factors including inflammatory activity. Given that matrix metalloproteinase (MMP)-9 has an important role in inflammation and cardiovascular disease, we hypothesized that circulating MMP-9 levels would be inversely related to total or single carotenoids in a general population cohort.

Methods: A well-characterized population-based cohort of 285 Swedish men and women (45-69 years) was used for the present study. The intake of carotenoid-rich fruits and vegetables was estimated from a food frequency questionnaire. Levels of MMP-9, C-reactive protein (CRP), interleukin (IL)-6 and six major carotenoids [ $\beta$-cryptoxanthine, $\alpha$-carotene, $\beta$ carotene, lutein (+ zeaxanthin) and lycopene] were determined in plasma.

Results: Lower plasma levels of total and single carotenoids were associated with lower dietary intake of carotenoids, older age, male sex, lower physical activity, higher alcohol consumption, higher body mass index (BMI), higher systolic and diastolic blood pressures, lower levels of total cholesterol and HDL cholesterol and higher levels of CRP, IL-6 and MMP-9. After multivariate adjustments, plasma levels of total carotenoids and provitamin A carotenoids ( $\beta$-cryptoxanthine, $\alpha$-carotene and $\beta$-carotene) remained independently associated with sex, dietary intake of carotenoids, BMI, HDL cholesterol and MMP-9, while associations with CRP and IL-6 were not maintained. Neither dietary intake of carotenoid-rich fruits and vegetables, nor vitamin supplement use was associated with MMP-9, CRP or IL-6 levels.

Conclusion: Plasma carotenoids were associated with a variety of factors including age, sex, dietary intake and metabolic variables. A new finding was the independent relationship in plasma between low provitamin A carotenoids and high MMP-9, suggesting a link between these carotenoids, matrix turnover and arterial remodelling. 


\section{Introduction}

An inverse association between circulating levels of carotenoids and cardiovascular disease, including early atherosclerosis, has been widely demonstrated [1-5]. Several large population-based studies have also shown that high consumption of carotenoid-rich fruits and vegetables is associated with a lower risk of cardiovascular disease and that the intake of carotenoids with provitamin A activity is inversely associated with the prevalence of carotid artery plaques [6-9]. Carotenoids are lipid-soluble organic pigments mainly present in red, orange and yellow fruits and green, leafy vegetables. Of the 50 carotenoids present in the human diet, only six are detectable in human plasma: $\beta$-cryptoxanthine, $\alpha$-carotene, $\beta$ carotene, lutein, zeaxanthin and lycopene. Among these, only $\beta$-cryptoxanthine, $\alpha$-carotene and $\beta$-carotene have provitamin A activity [10].

It has been widely proposed that measurement of carotenoids in plasma is a reliable method for assessing the amount of carotenoids in the diet. However, a number of previous population-based studies have demonstrated that plasma levels of carotenoids are only dependent to a limited extent on dietary intake of carotenoids. Instead, age, sex, excess weight, hypertension and smoking have been shown to correlate with carotenoid levels in the circulation [11-17]. Moreover, an inverse association between plasma carotenoids and systemic inflammation was a consistent finding in these studies [11-17]. In this respect, Creactive protein (CRP) has been the most studied marker, but interleukin (IL)-6 has also been assessed [15]. Furthermore, a modest association has been reported between dietary intake of carotenoid-rich fruits and vegetables and inflammatory markers [18-21]. It is speculated that the inverse relationship between carotenoids and inflammation is due to direct or indirect antiinflammatory and/or antioxidant actions of carotenoids themselves. Another possible explanation is that individuals with a low intake of fruit and vegetables are more likely to have an unhealthy lifestyle; for example, smoking, being overweight and having low levels of physical activity, all factors that are associated with increased inflammation.

Circulating levels of CRP and IL-6 have shown significant, though often modest, associations with cardiovascular disease in both cross-sectional and prospective studies [22]. Both CRP and IL-6 are general markers of any systemic inflammatory process taking place in the body. Therefore, there is an ongoing search for more specific biomarkers that can identify 
individuals with high-risk atherosclerotic disease, i.e. rupture-prone atherosclerotic plaques. Matrix metalloproteinases (MMPs), a family of $\mathrm{Zn}^{2+}$-dependent endopeptidases, have emerged as strong candidates. In the arterial wall, an increased expression of MMPs, in particular MMP-9, has been linked to remodelling, inflammation and matrix degradation [23]. Levels of MMP-9 in the circulation have been found to correlate with systemic inflammation but also with arterial hypertension and the prevalence of artery stenosis, plaque echolucency and plaque rupture [24-29]. Of interest, there is some experimental evidence that single carotenoids may suppress the expression and activity of MMP-9 in cells of different origin [30-32]. However, the relation between plasma levels of carotenoids and MMP-9 is not known, neither is the relation between dietary carotenoids and plasma MMP-9.

The aim of the present study was to determine the plasma levels of MMP-9, CRP, IL-6 and six major carotenoids as well as the dietary intake of carotenoid-rich fruits and vegetables in a well-characterized general population. Given that MMP-9 in plasma is a potential surrogate marker of arterial disease, we hypothesized to find a significant and inverse relationship between total or single carotenoids and MMP-9.

\section{Methods}

\section{Participants and study design}

Participants were recruited from the Life conditions, Stress and Health Study, as previously described [26]. Briefly, between 2003 and 2004, a random population sample from the southeast of Sweden was invited to participate (response rate 63\%). The 1007 study participants were evenly distributed with regard to sex and age (range 45-69 years), and were representative in terms of education level, employment rate and immigrant status. Exclusion criteria were dementia, psychiatric disorders and severe disease that would restrict participation. On a single occasion, participants underwent a brief health examination, questionnaires were completed and blood samples were collected in a fasting state. After resting for $5 \mathrm{~min}$, three repeated measurements of systolic and diastolic blood pressures at 2min intervals were performed in a sitting position (Omron, Rosny-sous-Bois, France, M5-1 Digital Automatic Blood Pressure Monitor). The mean of the second and third measurements was used for analyses. All blood samples were stored at $-70^{\circ}$ until required for analysis. Subanalyses were conducted using a randomly selected group of 284 men and women, representative of the whole cohort. The study design was approved by the Regional Ethical 
Review Board at Linköping University (02-0324) and written informed consent was obtained from all participants.

\section{Data from questionnaires}

A food frequency questionnaire (FFQ) with 92 country-specific food items was used to estimate the dietary intake of carotenoids [33]. Carotenoid-rich fruits were categorized as two separate items: citrus fruits (including juice drinks) and 'additional unspecified fruits' while carotenoid-rich vegetables were categorized as seven separate items: spinach, broccoli, cabbage, carrots, tomatoes, bell peppers and 'mixed' vegetables. Participants were asked how often, on average, they had consumed each food item during the previous year. The FFQ had predefined frequency categories giving each item a score from 1 to $8: 1=$ never; $2=1-3$ times per month; $3=1-2$ times per week; $4=3-4$ times per week; $5=5-6$ times per week; 6 $=$ once per day; $7=$ twice per day; $8=\geq 3$ times per day. The sum of the scores indicated the total intake of carotenoid-rich fruit and vegetables. The FFQ also included questions about regular vitamin supplementation ( $\geq 3$ times per week). Alcohol intake was estimated by combining frequency and typical amounts of different beverages, and divided into risk categories based on Swedish health recommendations for alcohol intake per week; for men: low $<110 \mathrm{~g}$, medium 110-160 g and high $>160 \mathrm{~g}$; for women: low $<88 \mathrm{~g}$, medium 80-110 g and high $>110 \mathrm{~g}$.

Physical activity was measured according to the methods used for population surveys conducted by the Public Health Science Centre in the County of Östergötland [34]. Two questions, 'How much physical exercise do you normally have in your everyday life?' and 'How much physical exercise do you have voluntarily, apart from the physical exercise above?', were combined to give an index with three categories: 1) inactive, 2) low to moderate physical activity and 3) a high level of physical activity. Participants were also questioned about smoking habits, medication use and medical diagnoses. To estimate selfreported ischaemic heart disease, participants were asked, 'Have you ever had any event of myocardial infarction or angina pectoris diagnosed by a medical doctor? (Yes/No/Don't know)'. A similar construct was used to capture self-reported diabetes.

\section{Biochemical analyses}

\section{Lipids and inflammatory markers}


Plasma levels of cholesterol and triglycerides were analysed by enzymatic colorimetric methods. CRP was measured in serum using a highly sensitive latex-enhanced turbidimetric immunoassay (Roche Diagnostics GmbH, Vienna, Austria) with a detection limit of 0.03 $\mathrm{mg} / \mathrm{L}$ and an inter-assay coefficient of variation $<2 \%$. IL-6 was measured in plasma by an enzyme-linked immunosorbent assay (ELISA) (Quantikine HS, R \& D Systems Europe Ltd, Abingdon, UK) with a detection limit of $0.04 \mathrm{pg} / \mathrm{mL}$ and an inter-assay coefficient of variation $<5 \%$. MMP-9 was measured in plasma using a Biotrak ELISA system (Amersham Biosciences, Uppsala, Sweden). This assay for MMP-9 measures MMP-9, pro-MMP-9 and the proMMP-9/tissue inhibitor metalloproteinase-1 complex. The detection limit was 0.6 $\mathrm{ng} / \mathrm{mL}$ and the interassay coefficient of variance was $<8 \%$.

\section{Plasma carotenoids}

Plasma levels of $\beta$-cryptoxanthine, $\alpha$-carotene, $\beta$-carotene, lutein (+ zeaxanthin) and lycopene were determined with high-performance liquid chromatography (HPLC) as previously described [35]. Because lutein and its stereo isomer zeaxanthin are structurally almost identical, this analysis does not discriminate between them and the sum of these carotenoids is presented as a single value; the plasma level of zeaxanthin normally represents less than $15 \%$ of the total value. All chemicals were purchased from Sigma-Aldrich (St. Louis, MO, USA). The validity of the HPLC method was ensured by including a reference sample that was calibrated against an external standard (SRM 968C) from the National Institute of Standards and Technology (NIST). The HPLC analysis was performed with a Constametric III pump (LDC, Riviera Beach, FL, USA) and a Chromolith Performance $\mathrm{C}_{18}$ column (Merck KGaA, Darmstadt, Germany). Carotenoids were detected with a spectrophotometer (Jasco UV-975, Japan Spectroscopic Company, Tokyo, Japan) set at $450 \mathrm{~nm}$. Concentrations were calculated from a standard curve generated from peak-height ratios of carotenoid levels in reference samples using the software CSW ${ }^{\circledR} 1.7$ (DataApex Ltd, Prague, The Czech Republic). The intra- and interassay coefficients of variation were between $5 \%$ and $7 \%$.

\section{Statistical analysis}

SPSS 18.0 (SPSS Inc) and Stata 11.0 (Stata Corp LP) were used for statistical analyses. The statistical significance of any difference between male and female subjects or groups based on top versus bottom tertiles of plasma carotenoids or dietary intake of carotenoids was tested using the Wilcoxon rank-sum (numerical data) or chi-square tests (categorical data). The Spearman rank correlation coefficient was used to determine univariate correlations between 
plasma carotenoids, dietary intake of carotenoids and potential confounders: age, sex, smoking, physical activity, alcohol intake, body mass index (BMI), systolic and diastolic blood pressures and plasma levels of lipids, lipoproteins, CRP, IL-6 and MMP-9. A series of four separate regression analyses were performed to test the associations between total carotenoids, provitamin A carotenoids or single carotenoids in plasma and: 1) age, sex and dietary intake of carotenoids, 2) smoking, physical activity, alcohol consumption and BMI, 3) systolic and diastolic blood pressure, total cholesterol, HDL cholesterol and triglycerides and 4) CRP, IL-6 and MMP-9. A final multiple regression model always included age, sex and total cholesterol plus variables that had shown significant associations in the four separate regression analyses. Data are presented as median (interquartile range) for continuous variables and as numbers ( $\%$ ) for discrete variables. Two-tailed $P$-values $<0.05$ were considered significant.

\section{Results}

The characteristics of the study population including demographic, physiological, behavioural and biochemical variables are given in Tables $1 \mathrm{a}$ and $\mathrm{b}$. Six men (4\%) and six women (4\%) reported that they had been diagnosed with ischaemic heart disease while 10 men (7\%) and eight women (6\%) reported having diabetes (two women had both ischaemic heart disease and diabetes). Sixteen men (11\%) and 18 women (13\%) were taking antihypertensive medication and six men (4\%) and three women (2\%) were treated with statins. Among statin users, two had ischaemic heart disease and two had diabetes. Compared with men, women had lower BMI, lower blood pressure and higher levels of HDL cholesterol. Women also consumed less alcohol and more carotenoid-rich fruits and vegetables, and reported more frequent use of multivitamin supplements. Women had higher plasma levels of total carotenoids, including all single carotenoids (except lycopene), and lower levels of IL-6 and MMP-9 than men. Levels of carotenoids and MMP-9 did not differ significantly between participants with and without self-reported ischaemic heart disease or diabetes (data not shown). On the other hand, statin users had significantly lower plasma levels of total carotenoids compared with non-statin users [0.74 (0.67-1.2) vs. $1.22(0.92-1.7) \mu \mathrm{mol} / \mathrm{L}$; $P=0.011]$, whereas MMP-9 levels did not differ between the two groups [36 (27-76) vs. 34 (23-51) $\mathrm{ng} / \mathrm{mL}]$. 
Plasma carotenoid levels were divided into tertiles and the bottom and top tertiles were compared in relation to age, sex and physiological, behavioural and biochemical variables (Tables 2a and b). The bottom tertile of total carotenoids was associated with being older, male and less physically active, and lower consumption of carotenoid-rich fruits and vegetables and higher consumption of alcohol. Low total carotenoids were also associated with having higher blood pressure, antihypertensive medication use, higher BMI and lower levels of total cholesterol and HDL cholesterol. Moreover, individuals in the bottom tertile of total carotenoids had significantly higher levels of CRP, IL-6 and MMP-9 compared with those in the top tertile. Significant differences in sex, dietary intake of carotenoids, smoking status, alcohol consumption, BMI, antihypertensive medication use and levels of total cholesterol, HDL cholesterol, triglycerides , IL-6 and MMP-9 were seen when comparing the bottom and top tertiles of all single provitamin A carotenoids ( $\beta$-cryptoxanthine, $\alpha$-carotene and $\beta$-carotene). A difference in age was only noted for lycopene, whereas differences in alcohol consumption, BMI and HDL cholesterol were associated with all individual carotenoids except lycopene.

Next we compared the bottom and top tertiles of dietary intake of carotenoids in relation to age, sex and physiological, behavioural and biochemical variables (Table 3). The estimated intake of carotenoid-rich fruit and vegetables was divided into tertiles based on the sum of the scores from the FFQ: bottom, $<25$; medium, 25-31; and top, $>31$. Individuals within the bottom tertile of carotenoid intake were more likely to be male and current smokers. They also had significantly lower plasma levels of all carotenoids. By contrast, the levels of CRP, IL-6 and MMP-9 did not differ between individuals with the bottom and top tertiles of carotenoid intake. As shown in Table 4, regular use of multivitamin supplements was associated with higher levels of total carotenoids and $\beta$-carotene, whereas the levels of $\beta$ cryptoxanthine, $\alpha$-carotene, lutein and lycopene did not differ. The levels of CRP, IL- 6 and MMP-9 were similar in users and non-users of multivitamin supplements.

Spearman rank correlation coefficients as a measure of the associations between dietary intake of carotenoids, total and single plasma carotenoids, age, sex and physiological, behavioural and biochemical variables are given in Table 5. Higher levels of total carotenoids in plasma were correlated with higher dietary intake of carotenoids, younger age, female sex, lower alcohol consumption, lower BMI, antihypertensive medication use, lower systolic and 
diastolic blood pressures, higher levels of total cholesterol and HDL cholesterol, and lower levels of triglycerides, CRP, IL-6 and MMP-9. Some of these relationships differed between the various single carotenoids; for example, lycopene was the only carotenoid that was associated with age but also the only one that lacked correlation with sex and HDL cholesterol. The individual carotenoids showed significant correlations with CRP, IL-6 and MMP-9 with few exceptions; there was no correlation between $\beta$-cryptoxanthine and CRP, or between lutein and MMP-9. The provitamin A carotenoids ( $\beta$-cryptoxanthine, $\alpha$-carotene and $\beta$-carotene) showed stronger correlations than lutein and lycopene with the estimated intake of carotenoid-rich fruit and vegetables. The weaker correlation between dietary intake of carotenoids and plasma concentrations of lutein and lycopene remained after including eggs (egg yolk is rich in lutein) and ketchup (rich in lycopene) in regression analyses. The dietary intake of carotenoids was not correlated with CRP, IL-6 or MMP-9 levels. The individual carotenoids were all inter-correlated, the strongest correlation being between $\alpha$-carotene and $\beta$-carotene $(r=0.85, P<0.001)$ and the weakest correlation between $\beta$-cryptoxanthine and lycopene $(r=0.18, P=0.002)$.

In a series of separate multiple regression analyses, we included total carotenoids, provitamin A carotenoids or single carotenoids as dependent variables and age, sex, carotenoid intake, smoking status, physical activity, alcohol intake, BMI, systolic and diastolic blood pressures and levels of total cholesterol, HDL cholesterol, triglycerides, CRP, IL-6 and MMP-9 as independent variables. The final multiple regression model with total carotenoids as the dependent variable included age, sex, carotenoid intake, BMI and levels of total cholesterol, HDL cholesterol, IL-6 and MMP-9 as independent variables. The final multiple regression models with the provitamin A carotenoids $\alpha$-carotene or $\beta$-carotene as dependent variables included age, sex, carotenoid intake, BMI, total cholesterol, HDL cholesterol and MMP-9 as independent variables. When $\beta$-cryptoxanthine was the dependent variable, age, sex, carotenoid intake, BMI, systolic blood pressure, total cholesterol, HDL cholesterol and MMP9 were used as independent variables. In the final model with lutein as the dependent variable, age, sex, BMI, systolic blood pressure, total cholesterol, HDL cholesterol and CRP were included as independent variables. The final multiple regression model with lycopene as the dependent variable included age, sex, alcohol intake, BMI, systolic blood pressure, total cholesterol and IL-6 as independent variables. 
As shown in Table 6, the factors that remained significantly associated with total carotenoids and provitamin A carotenoids in the final multiple regression models included age, sex, intake of carotenoid-rich fruits and vegetables, BMI, HDL cholesterol and MMP-9. The single provitamin A carotenoids ( $\beta$-cryptoxanthine, $\alpha$-carotene and $\beta$-carotene) also remained, or tended to remain, associated with plasma levels of MMP-9 in the fully adjusted models. The $\mathrm{R}$-squared values for carotenoids in the final multiple regression models were 0.14 (lutein), 0.17 ( $\beta$-cryptoxanthine), 0.20 (lycopene), 0.21 ( $\beta$-carotene), 0.27 ( $\alpha$-carotene), 0.27 (provitamin A carotenoids) and 0.31 (total carotenoids), and explained between 14\% and 31\% of the variability in plasma levels. The use of antihypertensive medication was strongly associated with both systolic and diastolic blood pressures (both $P<0.001$ ) and, therefore, not included in the regression models. However, adding antihypertensive medication post hoc to the final multiple regression models did not alter the findings. The presence of ischaemic heart disease or diabetes did not significantly affect the plasma levels of carotenoids or MMP9 and were, therefore, not included in the multiple regression models. Statin use was associated with lower carotenoid levels but the exclusion of statin users $(n=9)$ from the statistical analyses did not alter the results.

In the setting of a multiple regression model with dietary intake of carotenoids as the dependent variable and plasma carotenoids (total carotenoids, total provitamin A carotenoids, $\beta$-cryptoxanthine, $\alpha$-carotene or $\beta$-carotene), sex, smoking and MMP-9 as independent variables, independent associations remained between dietary intake and plasma levels of total carotenoids, provitamin A carotenoids and single provitamin A carotenoids (all $P<0.01$ ), sex $(P<0.001)$ and smoking $(P<0.01)$.

\section{Discussion}

In this population-based cross-sectional survey, total carotenoid levels in plasma were significantly associated with the intake of carotenoid-rich fruits and vegetables, but only to a limited extent. Among single carotenoids in plasma, the provitamin A carotenoids showed the strongest correlation with dietary intake. The modest relationship between plasma level and dietary intake of carotenoids was of the same magnitude as that observed in other population cohorts using a variety of FFQs $[11,14,16,17]$. However, the measurement errors in assessing the intake of carotenoid-rich fruits and vegetables may have attenuated the 
correlation between plasma levels and dietary intake of carotenoids. The FFQ used in our study reflects intake over 1 year and has been shown to underestimate the intake of fruits and vegetables when compared with a 7-day dietary record [33]. Besides lower dietary intake per se, a number of other factors including older age, male sex and metabolic factors were related to lower carotenoid levels in plasma. The lower plasma levels in men may be largely attributed to the dietary pattern as a significantly higher proportion of men, compared with women, were low-carotenoid consumers. However, after multivariate adjustments, male sex remained associated with lower concentrations of both total and single carotenoids, with the exception of lycopene. Higher plasma carotenoids, as well as higher dietary carotenoids, in women compared with men have been a consistent finding in many studies [11-14, 16, 17]. Brady et al [11], by relating the plasma levels of five major carotenoids in 400 individuals to the estimated intake of each carotenoid, found that female sex was associated with higher plasma levels and higher intake of all single carotenoids, except lycopene which did not differ between women and men in either plasma levels or dietary intake.

Furthermore, our finding of an independent and negative correlation between plasma carotenoids and BMI is in agreement with previous studies reporting inverse relationships between carotenoids and BMI, fat mass and waist-hip ratio [11-17]. The accumulation of carotenoids in adipose tissue has been proposed to explain the diminished levels of carotenoids in plasma. Likewise, the correlation between plasma carotenoids and lipoproteins, in particular HDL cholesterol, was an expected finding that may reflect the role of lipoproteins in the storage or transport of carotenoids. In line with other studies [11-17], we also found an inverse association between plasma carotenoids and hypertension but neither blood pressure levels nor antihypertensive medication use remained as independent determinants after adjustments. The lower carotenoid levels among statin users was an expected finding. We recently reported that carotenoid levels in plasma, if not adjusted for lipids, are significantly reduced during statin therapy [35].

Plasma levels of all single carotenoids showed inverse correlations with levels of CRP and IL6 in crude analyses. The association between inflammatory response and decreased carotenoid levels is well known. The levels of lutein, lycopene, $\alpha$-carotene and $\beta$-carotene have been shown to decrease in plasma during the acute-phase response and normalize with resolution of the inflammatory process, indicating that these carotenoids are consumed or redistributed during inflammation [36]. Inverse associations between CRP and carotenoid levels have also 
been demonstrated in several large population-based cross-sectional studies. The associations have remained for individual carotenoids, in particular lutein, $\alpha$-carotene and $\beta$-carotene, after adjustment for confounders such as dietary intake, age, sex, BMI and smoking status [11-17]. Few studies have investigated IL-6, the major inducer of CRP synthesis, but a longitudinal relation between carotenoids (lutein, $\alpha$-carotene and $\beta$-carotene) and IL- 6 has been demonstrated in a population of older women [15].

Unexpectedly, we found that neither total nor single carotenoid levels in plasma remained associated with IL-6 or CRP after adjustments for potential confounders. A plausible explanation for this may be that CRP levels in our study cohort were generally low compared with previously reported levels [11-17]. It is interesting that the association between total carotenoids and MMP-9 remained in the fully adjusted model. Among single carotenoids, the independent association with MMP-9 was found to be restricted to the group of provitamin A carotenoids.

Like CRP and IL-6, MMP-9 in plasma may be regarded as a general indicator of inflammation but it is now also recognized as a marker of hypertension and early atherosclerosis, mainly due to its key role in extracellular matrix remodelling. In animal models, the onset of hypertension is accompanied by increased MMP-9 activity [37]. Moreover, in a prospective study of non-hypertensive subjects, high levels of MMP-9 were predictive of blood pressure progression [28]. It has also been shown that circulating levels of MMP-9 correlate with intima-media thickness and atherosclerotic plaque burden in human carotid and femoral arteries [25, 27]. Expression of MMP-9 is increased in rupture-prone plaques compared to stable plaques, and the increased plasma levels of MMP-9 in clinical manifestations of coronary plaque rupture are believed to reflect, at least in part, leakage from arterial lesions [24]. Another major source of MMP-9 in human plasma is the leukocyte [38]. Leukocyte-derived MMP-9 plays an additional role in atherogenesis by facilitating the adhesion and migration of cells into the arterial wall. The effect of carotenoids on MMP-9 in humans is largely unknown although experimental models have indicated interesting interactions between carotenoids and MMP-9. Carotenoids, in particular $\beta$-carotene, have been shown to inhibit the synthesis and activation of MMP-9 in cell lines and mouse models [30-32]. Emerging evidence indicates that retinoids, the metabolically active derivatives of vitamin A, exhibit effects on vascular cells and have anti-inflammatory properties that may be 
highly relevant to atherogenesis [39]. Interestingly, several studies have demonstrated that alltrans retinoic acid selectively downregulates MMP-9 in a variety of human cells such as primary monocytes, bronchoalveolar lavage cells and breast cancer cells [40-42].

The estimated intake of carotenoid-rich fruits and vegetables was not related to levels of CRP, IL-6 or MMP-9. Some epidemiological studies have reported modest inverse associations between the intake of carotenoid-rich fruits and vegetables and inflammatory markers [18-21] whereas others have not shown such relationships [13]. The inconsistent results may reflect methodological difficulties in measuring dietary intake. One remarkable observation was that users of multivitamin supplements exhibited isolated increases in $\beta$-carotene but no change in CRP, IL-6 or MMP-9 levels compared with non-users. In this regard, it may be of interest to note that large intervention trials have failed to show any beneficial effects of supplementation with $\beta$-carotene in the prevention of cardiovascular events, despite increases in plasma levels $[43,44]$.

Several limitations should be taken into account when interpreting our findings. Potential errors that are associated with nutrient estimation from FFQs include misrecordings and poor discrimination between answer categories. The variability in plasma levels of total carotenoids and provitamin A carotenoids explained by our model was around 30\% indicating that much of the variability is due to unknown factors. However, under-reporting of fruit and vegetable intake in the FFQ may have contributed to underestimated R-squared values. Other limitations involve the small size of the population sample, thus major conclusions could not be drawn from subgroup analyses. In addition, the cross-sectional design precluded conclusions about causality. Although our findings were in the expected duration, due to the large number of comparisons, some associations may have arisen by chance. It is also possible that the association between plasma levels of provitamin A carotenoids and MMP-9 reflects a relation of both to some other factor and/or that both are merely markers of an unknown physiological process, rather than being co-actors.

To summarize, not only dietary intake of fruits and vegetables but also a number of other factors including age, sex, BMI and HDL cholesterol were independent determinants of the levels of carotenoids, in particular provitamin A carotenoids, in plasma. The widely described relationships between plasma carotenoids and the general inflammatory markers CRP and IL- 
6 were not maintained after adjustments for potential confounders. Instead, the independent relationship between plasma levels of provitamin A carotenoids and MMP-9 was a novel finding that may shed new light on the mechanism behind the inverse relation between carotenoids and cardiovascular risk. This calls for further investigation and at present we can only speculate that provitamin A carotenoids have atheroprotective effects by interfering with the turnover and degradation of the extracellular matrix in the arterial wall.

\section{Funding}

This study was supported by the Swedish Heart-Lung Foundation, the Swedish Research Council and Linköping University.

\section{Conflict of Interest Statement}

No conflict of interest was declared. 


\section{References}

1 Street DA, Comstock GW, Salkeld RM, Schuep W, Klag MJ. Serum antioxidants and myocardial infarction. Are low levels of carotenoids and alpha-tocopherol risk factors for myocardial infarction? Circulation 1994; 90: 1154-61.

2 Ford ES, Giles WH. Serum vitamins, carotenoids, and angina pectoris: findings from the National Health and Nutrition Examination Survey III. Ann Epidemiol 2000; 10: 10616.

3 Buijsse B, Feskens EJ, Schlettwein-Gsell D, Ferry M, Kok FJ, Kromhout D, de Groot LC. Plasma carotene and alpha-tocopherol in relation to $10-y$ all-cause and causespecific mortality in European elderly: the Survey in Europe on Nutrition and the Elderly, a Concerted Action (SENECA). Am J Clin Nutr 2005; 82: 879-86.

$4 \quad$ Shardell MD, Alley DE, Hicks GE, El-Kamary SS, Miller RR, Semba RD, Ferrucci L. Low-serum carotenoid concentrations and carotenoid interactions predict mortality in US adults: the Third National Health and Nutrition Examination Survey. Nutr Res 2011; 31: 17889.

$5 \quad$ Karppi J, Kurl S, Laukkanen JA, Rissanen TH, Kauhanen J. Plasma carotenoids are related to intima--media thickness of the carotid artery wall in men from eastern Finland. J Intern Med 2011; 270: 478-85.

$6 \quad$ Kritchevsky SB, Tell GS, Shimakawa T, et al. Provitamin A carotenoid intake and carotid artery plaques: the Atherosclerosis Risk in Communities Study. Am J Clin Nutr 1998; 68: 726-33. 
7 Liu S, Manson JE, Lee IM, Cole SR, Hennekens CH, Willett WC, Buring JE. Fruit and vegetable intake and risk of cardiovascular disease: the Women's Health Study. Am J Clin Nutr 2000; 72: 922-8.

8 Liu S, Lee IM, Ajani U, Cole SR, Buring JE, Manson JE. Intake of vegetables rich in carotenoids and risk of coronary heart disease in men: The Physicians' Health Study. Int J Epidemiol 2001; 30: 130-5.

$9 \quad$ Crowe FL, Roddam AW, Key TJ, et al. Fruit and vegetable intake and mortality from ischaemic heart disease: results from the European Prospective Investigation into Cancer and Nutrition (EPIC)-Heart study. Eur Heart J 2011; 32: 1235-43.

10 Grune T, Lietz G, Palou A, et al. Beta-carotene is an important vitamin A source for humans. J Nutr 2010; 140: 2268S-85S.

11 Brady WE, Mares-Perlman JA, Bowen P, Stacewicz-Sapuntzakis M. Human serum carotenoid concentrations are related to physiologic and lifestyle factors. J Nutr 1996; 126: $129-37$.

12 Kritchevsky SB, Bush AJ, Pahor M, Gross MD. Serum carotenoids and markers of inflammation in nonsmokers. Am J Epidemiol 2000; 152: 1065-71.

13 Ford ES, Liu S, Mannino DM, Giles WH, Smith SJ. C-reactive protein concentration and concentrations of blood vitamins, carotenoids, and selenium among United States adults. Eur J Clin Nutr 2003; 57: 1157-63.

14 Gruber M, Chappell R, Millen A, et al. Correlates of serum lutein + zeaxanthin: findings from the Third National Health and Nutrition Examination Survey. J Nutr 2004; 134: 2387-94.

15 Walston J, Xue Q, Semba RD, et al. Serum antioxidants, inflammation, and total mortality in older women. Am J Epidemiol 2006; 163: 18-26.

16 Hozawa A, Jacobs DR, Jr., Steffes MW, Gross MD, Steffen LM, Lee DH.

Relationships of circulating carotenoid concentrations with several markers of inflammation, oxidative stress, and endothelial dysfunction: the Coronary Artery Risk Development in Young Adults (CARDIA)/Young Adult Longitudinal Trends in Antioxidants (YALTA) study. Clin Chem 2007; 53: 447-55.

17 Wang L, Gaziano JM, Norkus EP, Buring JE, Sesso HD. Associations of plasma carotenoids with risk factors and biomarkers related to cardiovascular disease in middleaged and older women. Am J Clin Nutr 2008; 88: 747-54.

18 Watzl B, Kulling SE, Moseneder J, Barth SW, Bub A. A 4-wk intervention with high intake of carotenoid-rich vegetables and fruit reduces plasma C-reactive protein in healthy, nonsmoking men. Am J Clin Nutr 2005; 82: 1052-8.

19 Nettleton JA, Steffen LM, Mayer-Davis EJ, Jenny NS, Jiang R, Herrington DM, Jacobs DR, Jr. Dietary patterns are associated with biochemical markers of inflammation and endothelial activation in the Multi-Ethnic Study of Atherosclerosis (MESA). Am J Clin Nutr 2006; 83: 1369-79.

20 Holt EM, Steffen LM, Moran A, et al. Fruit and vegetable consumption and its relation to markers of inflammation and oxidative stress in adolescents. J Am Diet Assoc 2009; 109: 414-21.

21 Helmersson J, Arnlov J, Larsson A, Basu S. Low dietary intake of beta-carotene, alpha-tocopherol and ascorbic acid is associated with increased inflammatory and oxidative stress status in a Swedish cohort. Br J Nutr 2009; 101: 1775-82.

22 Pai JK, Pischon T, Ma J, et al. Inflammatory markers and the risk of coronary heart disease in men and women. N Engl J Med 2004; 351: 2599-610. 
23 Bäck M, Ketelhuth DF, Agewall S. Matrix metalloproteinases in atherothrombosis. Prog Cardiovasc Dis 2010; 52: 410-28.

24 Fukuda D, Shimada K, Tanaka A, et al. Comparison of levels of serum matrix metalloproteinase- 9 in patients with acute myocardial infarction versus unstable angina pectoris versus stable angina pectoris. Am J Cardiol 2006; 97: 175-80.

25 Taurino M, Raffa S, Mastroddi M, Visco V, Rizzo L, Torrisi MR, Faraglia V. Metalloproteinase expression in carotid plaque and its correlation with plasma levels before and after carotid endarterectomy. Vasc Endovascular Surg 2007; 41: 516-21.

26 Garvin P, Nilsson L, Carstensen J, Jonasson L, Kristenson M. Circulating matrix metalloproteinase- 9 is associated with cardiovascular risk factors in a middle-aged normal population. PLoS One 2008; 3: e1774.

27 Olson FJ, Schmidt C, Gummesson A, Sigurdardottir V, Hulthe J, Wiklund O, Fagerberg B. Circulating matrix metalloproteinase 9 levels in relation to sampling methods, femoral and carotid atherosclerosis. J Intern Med 2008; 263: 626-35.

28 Dhingra R, Pencina MJ, Schrader $\mathrm{P}$, et al. Relations of matrix remodeling biomarkers to blood pressure progression and incidence of hypertension in the community. Circulation 2009; 119: 1101-7.

29 Romero JR, Vasan RS, Beiser AS, Polak JF, Benjamin EJ, Wolf PA, Seshadri S. Association of carotid artery atherosclerosis with circulating biomarkers of extracellular matrix remodeling: the Framingham Offspring Study. J Stroke Cerebrovasc Dis 2008; 17: 4127.

30 Guruvayoorappan C, Kuttan G. Beta-carotene inhibits tumor-specific angiogenesis by altering the cytokine profile and inhibits the nuclear translocation of transcription factors in B16F-10 melanoma cells. Integrative cancer therapies 2007; 6: 25870.

31 Minami Y, Kawabata K, Kubo Y, et al. Peroxidized cholesterol-induced matrix metalloproteinase- 9 activation and its suppression by dietary beta-carotene in photoaging of hairless mouse skin. J Nutr Biochem 2009; 20: 389-98.

32 Terao J, Minami Y, Bando N. Singlet molecular oxygen-quenching activity of carotenoids: relevance to protection of the skin from photoaging. Journal of clinical biochemistry and nutrition 2011; 48: 57-62.

33 Khani BR, Ye W, Terry P, Wolk A. Reproducibility and validity of major dietary patterns among Swedish women assessed with a food-frequency questionnaire. J Nutr 2004; 134: $1541-5$.

$34 \quad$ Kallings LV, Leijon M, Hellenius ML, Stahle A. Physical activity on prescription in primary health care: a follow-up of physical activity level and quality of life. Scand J Med Sci Sports 2008; 18: 154-61.

35 Ryden M, Leanderson P, Kastbom KO, Jonasson L. Effects of simvastatin on carotenoid status in plasma. Nutr Metab Cardiovasc Dis 2010.

36 Gray A, McMillan DC, Wilson C, Williamson C, O'Reilly DS, Talwar D. The relationship between the acute changes in the systemic inflammatory response, lipid soluble antioxidant vitamins and lipid peroxidation following elective knee arthroplasty. Clin Nutr 2005; 24: 746-50.

$37 \quad$ Flamant M, Placier S, Dubroca C, et al. Role of matrix metalloproteinases in early hypertensive vascular remodeling. Hypertension 2007; 50: 212-8. 
38 Jonsson S, Lundberg A, Kalvegren H, Bergstrom I, Szymanowski A, Jonasson L. Increased levels of leukocyte-derived MMP-9 in patients with stable angina pectoris. PLoS One 2011; 6: e19340.

39 Rhee EJ, Nallamshetty S, Plutzky J. Retinoid metabolism and its effects on the vasculature. Biochim Biophys Acta 2012; 1821: 230-40.

$40 \quad$ Frankenberger M, Hauck RW, Frankenberger B, Haussinger K, Maier KL, Heyder J, Ziegler-Heitbrock HW. All trans-retinoic acid selectively down-regulates matrix metalloproteinase-9 (MMP-9) and up-regulates tissue inhibitor of metalloproteinase-1 (TIMP-1) in human bronchoalveolar lavage cells. Mol Med 2001; 7: 263-70.

41 Liu $\mathrm{H}$, Zang C, Fenner MH, Possinger K, Elstner E. PPARgamma ligands and ATRA inhibit the invasion of human breast cancer cells in vitro. Breast Cancer Res Treat 2003; 79: 63-74.

42 Jalian HR, Liu PT, Kanchanapoomi M, Phan JN, Legaspi AJ, Kim J. All-trans retinoic acid shifts Propionibacterium acnes-induced matrix degradation expression profile toward matrix preservation in human monocytes. J Invest Dermatol 2008; 128: 2777-82. 43 Hennekens $\mathrm{CH}$, Buring JE, Manson JE, et al. Lack of effect of long-term supplementation with beta carotene on the incidence of malignant neoplasms and cardiovascular disease. N Engl J Med 1996; 334: 1145-9.

$44 \quad$ Virtamo J, Rapola JM, Ripatti S, Heinonen OP, Taylor PR, Albanes D, Huttunen JK. Effect of vitamin $E$ and beta carotene on the incidence of primary nonfatal myocardial infarction and fatal coronary heart disease. Arch Intern Med 1998; 158: 668-75. 
Table 1a. Characteristics including demographic, physiological, behavioural and lipid variables in men and women of the study cohort. Data are given as median (interquartile range) or number $(\%)$.

\begin{tabular}{|l|l|l|c|}
\hline & $\begin{array}{l}\text { Men } \\
n=140\end{array}$ & $\begin{array}{l}\text { Women } \\
n=144\end{array}$ & $P$-value \\
\hline Age, years & $57(52-62)$ & $57(51-63)$ & 0.807 \\
\hline $\begin{array}{l}\text { Low intake of carotenoid-rich } \\
\text { fruits and vegetables }\end{array}$ & $61(44)$ & $31(22)$ & $<0.001$ \\
\hline $\begin{array}{l}\text { High intake of carotenoid-rich } \\
\text { fruits and vegetables }\end{array}$ & $26(19)$ & $65(45)$ & $<0.001$ \\
\hline Vitamin supplement intake & $24(17)$ & $54(38)$ & $<0.001$ \\
\hline Smoker & $27(19)$ & $27(19)$ & 0.908 \\
\hline Physically inactive & $6(4)$ & $7(5)$ & 0.798 \\
\hline High level of physical activity & $19(14)$ & $30(21)$ & 0.092 \\
\hline Low alcohol consumption & $94(67)$ & $130(90)$ & $<0.001$ \\
\hline High alcohol consumption & $25(18)$ & $3(2)$ & $<0.001$ \\
\hline BMI, kg/m ${ }^{2}$ & $27(25-30)$ & $26(23-29)$ & 0.005 \\
\hline Antihypertensive medication use & $16(11)$ & $18(13)$ & 0.781 \\
\hline Systolic blood pressure, mmHg & $133(121-144)$ & $128(113-146)$ & 0.052 \\
\hline Diastolic blood pressure, mmHg & $83(78-91)$ & $79(74-90)$ & 0.041 \\
\hline Total cholesterol, mmol/L & $5.5(4.8-6.2)$ & $5.6(5.0-6.1)$ & 0.455 \\
\hline HDL cholesterol, mmol/L & $1.4(1.2-1.6)$ & $1.7(1.5-2.0)$ & $<0.001$ \\
\hline
\end{tabular}


${ }^{1}$ Low intake of carotenoid-rich fruits and vegetables includes the bottom tertile of dietary intake, score $<25$; high intake of carotenoid-rich fruits and vegetables includes the top tertile of dietary intake, score $>31$.

Table 1b. Plasma levels of total and single carotenoids, CRP, IL-6 and MMP-9 in men and women of the study cohort. Data are given as median (interquartile range).

\begin{tabular}{|l|l|l|c|}
\hline & $\begin{array}{l}\text { Men } \\
n=140\end{array}$ & $\begin{array}{l}\text { Women } \\
n=144\end{array}$ & $P$-value \\
\hline Total carotenoids, $\mu \mathrm{mol} / \mathrm{L}$ & $1.03(0.77-1.33)$ & $1.44(1.11-1.94)$ & $<0.001$ \\
\hline$\beta$-cryptoxanthine, $\mu \mathrm{mol} / \mathrm{L}$ & $0.07(0.04-0.12)$ & $0.12(0.08-0.18)$ & $<0.001$ \\
\hline$\alpha$-carotene, $\mu \mathrm{mol} / \mathrm{L}$ & $0.08(0.05-0.12)$ & $0.13(0.09-0.26)$ & $<0.001$ \\
\hline$\beta$-carotene, $\mu \mathrm{mol} / \mathrm{L}$ & $0.26(0.18-0.39)$ & $0.45(0.30-0.73)$ & $<0.001$ \\
\hline Lutein, $\mu \mathrm{mol} / \mathrm{L}$ & $0.25(0.18-0.31)$ & $0.28(0.20-0.36)$ & 0.004 \\
\hline Lycopene, $\mu \mathrm{mol} / \mathrm{L}$ & $0.34(0.19-0.47)$ & $0.37(0.25-0.49)$ & 0.114 \\
\hline CRP, $\mathrm{mg} / \mathrm{L}$ & $0.86(0.24-2.00)$ & $0.62(0.27-1.90)$ & 0.441 \\
\hline IL-6, $\mathrm{pg} / \mathrm{ml}$ & $1.80(1.30-2.60)$ & $1.60(1.10-2.40)$ & 0.034 \\
\hline MMP-9, ng/ml & $39(27-57)$ & $31(21-46)$ & $<0.001$ \\
\hline
\end{tabular}


25

26

28

29

31

32

33

34

35

37

38

39

40

41

42
43

44

45

46

47

48

49

51

52

54

55

57

58

59

60 \\ Page 21 of 29}

Journal of Internal Medicine

1

.

.

17

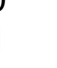

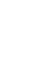

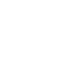

7

10

.

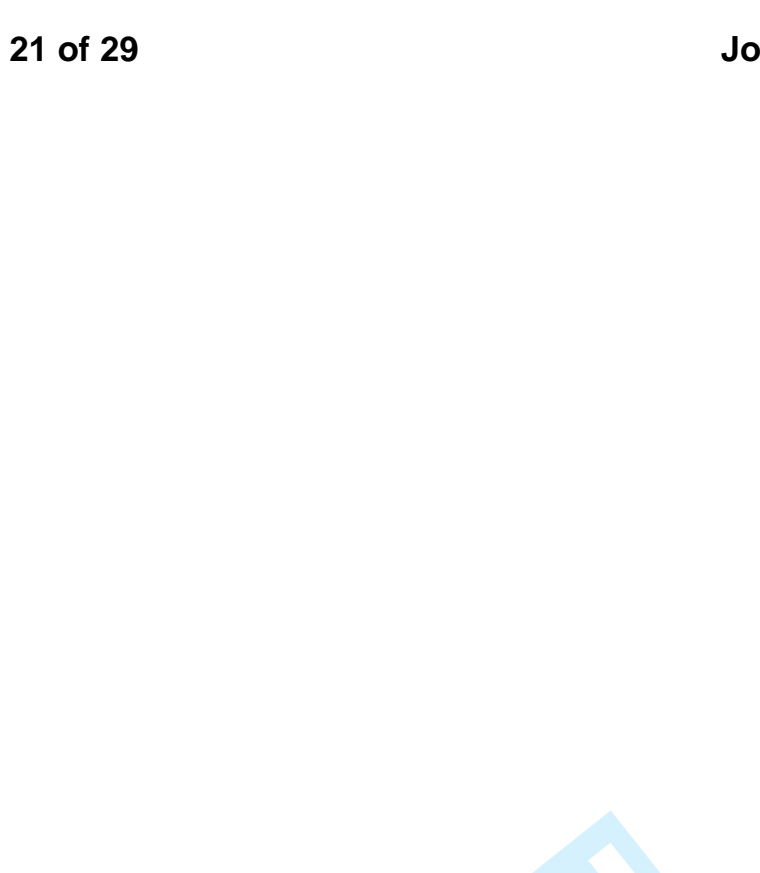


Table 2a. Distribution of demographic, physiological, behavioural and biochemical variables in the bottom (t1) and top tertiles ( $\mathrm{t} 3$ ) of total carotenoids and individual carotenoids (lutein and lycopene) in plasma. Data are given as median (interquartile range) or percentage.

\begin{tabular}{|c|c|c|c|c|c|c|c|c|c|}
\hline \multirow{2}{*}{$\begin{array}{l}10 \\
11 \\
12\end{array}$} & \multicolumn{3}{|c|}{ Total carotenoids } & \multicolumn{3}{|c|}{ Lutein } & \multicolumn{3}{|c|}{ Lycopene } \\
\hline & t1 $(n=94)$ & t3 $(n=94)$ & $P$-value & t1 $(n=96)$ & t3 $(n=96)$ & $P$-value & t1 $(n=93)$ & t3 $(n=92)$ & $P$-value \\
\hline 1 1)ge & \begin{tabular}{|l}
$59(54-65)$ \\
\end{tabular} & $56(50-61)$ & 0.012 & \begin{tabular}{|l}
$58(51-62)$ \\
\end{tabular} & $57(51-62)$ & 0.407 & $61(57-66)$ & $53(49-59)$ & $<0.001$ \\
\hline 1Stex, \% female & 30 & 72 & $<0.001$ & 47 & 60 & 0.060 & 43 & 54 & 0.123 \\
\hline $\begin{array}{l}16 \text { ow carotenoid-rich fruit } \\
16 \text { and vegetable intake }\end{array}$ & 41 & 18 & $<0.001$ & 33 & 25 & 0.204 & 41 & 27 & 0.050 \\
\hline $\begin{array}{l}\text { High carotenoid-rich fruit } \\
18 \text { and vegetable intake }\end{array}$ & 16 & 49 & $<<0.001$ & 30 & 42 & 0.098 & 24 & 40 & 0.016 \\
\hline S20 & 24 & 13 & 0.208 & 20 & 12 & 0.112 & 20 & 22 & 0.827 \\
\hline 29hysically inactive & 5 & 6 & 0.746 & 6 & 5 & 0.772 & 4 & 9 & 0.139 \\
\hline $\begin{array}{l}24 \text { igh level of physical } \\
23 \text { divity }\end{array}$ & 12 & 23 & 0.048 & 13 & 18 & 0.357 & 16 & 26 & 0.121 \\
\hline $\begin{array}{l}24 \text { ow alcohol consumption, } \\
25\end{array}$ & 77 & 85 & 0.201 & 75 & 84 & 0.114 & 82 & 71 & 0.098 \\
\hline${ }_{26}^{2} 6$ igh alcohol consumption, & 15 & 4 & 0.014 & 16 & 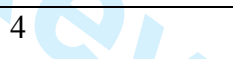 & 0.008 & 11 & 12 & 0.775 \\
\hline $\begin{array}{l}28 \mathrm{BMI}, \mathrm{kg} / \mathrm{m}^{2} \\
28\end{array}$ & $28(25-30)$ & $25(23-27)$ & $<0.001$ & $27(25-30)$ & $25(23-27)$ & $<0.001$ & $26(24-30)$ & $26(23-28)$ & 0.089 \\
\hline $\begin{array}{l}\text { 29ntihypertensive medication } \\
3 \mathrm{Q} \text { e }\end{array}$ & 23 & 5 & $<0.001$ & 15 & 8 & $<0.001$ & 19 & 3 & $<0.001$ \\
\hline $\begin{array}{l}33 \text { iastolic blood pressure, } \\
34 \mathrm{mHg}\end{array}$ & $86(79-95)$ & $78(72-85)$ & $<0.001$ & $83(77-91)$ & $79(76-87)$ & 0.064 & $85(78-96)$ & $79(74-85)$ & $<0.001$ \\
\hline $350 t a l$ cholesterol, $\mathrm{mmol} / \mathrm{L}$ & $5.20(4.67-5.90)$ & $5.80(5.10-6.30)$ & $<0.001$ & $5.40(4.80-6.00)$ & $5.80(5.03-6.30)$ & 0.006 & $5.30(4.80-6.00)$ & $5.75(5.00-6.38)$ & 0.012 \\
\hline $\begin{array}{l}36 \mathrm{DL} \text { cholesterol, } \mathrm{mmol} / \mathrm{L} \\
37\end{array}$ & $1.40(1.20-1.70)$ & $1.70(1.48-2.00)$ & $<0.001$ & $1.50(1.20-1.70)$ & $1.70(1.40-1.90)$ & $<0.001$ & $1.50(1.30-1.85)$ & $1.6(1.40-1.90)$ & 0.123 \\
\hline 3 Griglycerides, $\mathrm{mmol} / \mathrm{L}$ & $1.13(0.95-1.80)$ & $0.98(0.79-1.33)$ & $<0.001$ & $1.20(0.89-1.60)$ & $0.98(0.79-1.33)$ & $<0.001$ & $1.20(0.87-1.60)$ & $1.00(0.79-1.50)$ & 0.081 \\
\hline $3 \mathrm{RP}_{\mathrm{R}} \mathrm{mg} / \mathrm{L}$ & $1.37(0.39-2.76)$ & $0.42(0.19-1.11)$ & $<0.001$ & $1.26(0.23-2.79)$ & $0.60(0.26-1.57)$ & 0.071 & $1.19(0.29-2.59)$ & $0.52(0.19-1.61)$ & 0.008 \\
\hline
\end{tabular}




\begin{tabular}{|l|l|l|l|l|l|l|l|l|l|}
\hline SIL-6, pg/mL & $2.24(1.41-3.86)$ & $1.54(1.06-2.01)$ & $<\mathbf{0 . 0 0 1}$ & $1.88(1.20-2.87)$ & $1.64(1.15-2.08)$ & 0.052 & $1.91(1.33-3.02)$ & $1.44(1.05-2.06)$ & $<\mathbf{0 . 0 0 1}$ \\
\hline 6MMP-9, ng/mL & $45.6(28.8-68.5)$ & $31.4(19.2-46.4)$ & $<\mathbf{0 . 0 0 1}$ & $33.0(21.8-62.5)$ & $32.5(21.5-49.5)$ & 0.359 & $36.9(26.3-61.9)$ & $31.5(20.6-48.5)$ & $\mathbf{0 . 0 1 4}$ \\
\hline
\end{tabular}

${ }^{1}$ Low intake of carotenoid-rich fruits and vegetables includes the bottom tertile of dietary intake, score $<25$; high intake of carotenoid-rich fruits and vegetables includes the top tertile of dietary intake, score $>31$. Total carotenoids: $\mathrm{t} 1<0.99$ and $\mathrm{t} 3>1.47 \mu \mathrm{mol} / \mathrm{L} ;$ lutein: $\mathrm{t} 1<0.22$ and $\mathrm{t} 3>0.30$ $\mu \mathrm{mol} / \mathrm{L}$. lycopene: $\mathrm{t} 1 \mathrm{n}<0.28$ and $\mathrm{t} 3>0.42 \mu \mathrm{mol} / \mathrm{L}$. 
Table 2b. Distribution of demographic, physiological, behavioural and biochemical variables in the bottom ( $\mathrm{t} 1)$ and top tertiles ( $\mathrm{t} 3$ ) of individual provitamin A carotenoids ( $\beta$-cryptoxanthine, $\alpha$-carotene and $\beta$-carotene) in plasma. Data are given as median (interquartile range) or percentage.

Low carotenoid-rich fruit and 1 1ggetable intake $^{1}$

20igh carotenoid-rich fruit and 2 tegetable intake $^{1}$

$$
22
$$

23 moker

\section{4ysically inactive}

25igh level of physical activity

\begin{tabular}{|c|c|c|}
\hline \multicolumn{3}{|c|}{$\beta$-cryptoxanthine } \\
\hline $\begin{array}{l}\mathrm{t} 1 \\
n=100\end{array}$ & $\begin{array}{l}\mathrm{t} 3 \\
n=100\end{array}$ & $P$-value \\
\hline $57(50-63)$ & $58(51-63)$ & 0.942 \\
\hline 30 & 69 & $<0.001$ \\
\hline 47 & 18 & $<0.001$ \\
\hline 16 & 48 & $<0.001$ \\
\hline 27 & 14 & 0.023 \\
\hline 5 & 4 & 0.758 \\
\hline 14 & 24 & 0.078 \\
\hline 74 & 84 & 0.082 \\
\hline 15 & 6 & 0.038 \\
\hline $27(24-30)$ & $25(23-28)$ & 0.003 \\
\hline 13 & 9 & $<0.001$ \\
\hline $134(119-146)$ & $128(113-143)$ & 0.092 \\
\hline $83(77-91)$ & $81(76-89)$ & 0.183 \\
\hline $5.25(4.73-5.98)$ & $5.90(5.10-6.28)$ & $<0.001$ \\
\hline $1.50(1.23-1.70)$ & $1.70(1.40-2.00)$ & $<0.001$ \\
\hline $1.20(0.90-1.78)$ & $1.00(0.79-1.40)$ & 0.010 \\
\hline
\end{tabular}

\begin{tabular}{|c|c|c|}
\hline \multicolumn{3}{|c|}{$\alpha$-carotene } \\
\hline $\mathrm{t} 1$ & t3 & $P$-value \\
\hline$n=93$ & $n=92$ & \\
\hline $57(50-62)$ & $57(52-62)$ & 0.822 \\
\hline 28 & 73 & $<0.001$ \\
\hline 40 & 22 & 0.010 \\
\hline 17 & 50 & $<0.001$ \\
\hline 23 & 12 & 0.049 \\
\hline 6 & 5 & 0.657 \\
\hline 17 & 23 & 0.324 \\
\hline 71 & 86 & 0.009 \\
\hline 19 & + & $<0.001$ \\
\hline $27(24-30)$ & 27 (24-29) & $<0.001$ \\
\hline 20 & 6 & $<0.001$ \\
\hline $135(122-150)$ & $125(112-140)$ & $<0.001$ \\
\hline $85(78-91)$ & $79(74-87)$ & 0.002 \\
\hline $5.20(4.70-6.00)$ & $5.6(5.1-6.2)$ & 0.002 \\
\hline $1.40(1.25-1.70)$ & $1.7(1.5-2.0)$ & $<0.001$ \\
\hline $1.20(0.85-1.80)$ & $0.98(0.78-1.20)$ & $<0.001$ \\
\hline
\end{tabular}

\begin{tabular}{|l|l|c|}
\hline \multicolumn{3}{|c|}{$\beta$-carotene } \\
\hline $\begin{array}{l}\mathrm{t} 1 \\
n=93\end{array}$ & $\begin{array}{l}\mathrm{t} 3 \\
n=92\end{array}$ & $P$-value \\
\hline $58(52-62)$ & $57(50-62)$ & 0.583 \\
\hline 26 & 75 & $<\mathbf{0 . 0 0 1}$ \\
\hline 46 & 22 & $<\mathbf{0 . 0 0 1}$ \\
\hline 19 & & \\
\hline 29 & 51 & $<\mathbf{0 . 0 0 1}$ \\
\hline 4 & & \\
\hline 13 & 16 & $\mathbf{0 . 0 3 3}$ \\
\hline 69 & 6 & 0.668 \\
\hline 18 & 26 & $\mathbf{0 . 0 3 6}$ \\
\hline $27(25-30)$ & 87 & $\mathbf{0 . 0 0 3}$ \\
\hline 22 & 3 & $<\mathbf{0 . 0 0 1}$ \\
\hline $137(123-150)$ & $25(23-27)$ & $<\mathbf{0 . 0 0 1}$ \\
\hline $86(78-95)$ & $124(111-136)$ & $<\mathbf{0 . 0 0 1}$ \\
\hline $5.20(4.88-6.00)$ & $79(73-85)$ & $<\mathbf{0 . 0 0 1}$ \\
\hline $1.40(1.20-1.70)$ & $5.70(5.10-6.20)$ & $\mathbf{0 . 0 1 3}$ \\
\hline $1.35(0.95-2.00)$ & $1.70(1.50-2.00)$ & $<\mathbf{0 . 0 0 1}$ \\
\hline & $0.94(0.78-1.20)$ & $<\mathbf{0 . 0 0 1}$ \\
\hline
\end{tabular}




\section{Page 25 of 29}

Journal of Internal Medicine

\begin{tabular}{|c|c|c|c|c|c|c|c|c|c|}
\hline $5 \mathrm{CRP}, \mathrm{mg} / \mathrm{L}$ & $0.86(0.23-2.47)$ & $0.59(0.24-1.87)$ & 0.213 & $1.13(0.33-2.56)$ & $0.5(0.2-1.5)$ & 0.003 & $1.26(0.33-2.82)$ & $0.42(0.19-1.47)$ & $<0.001$ \\
\hline 9िL-6, pg/mL & $1.91(1.33-3.02)$ & $1.44(1.05-2.06)$ & $<0.001$ & $2.00(1.29-3.02)$ & $1.4(0.9-1.9)$ & $<0.001$ & $2.04(1.38-3.79)$ & $1.44(1.00-2.01)$ & $<0.001$ \\
\hline MMP-9, ng/mL & 36.9 (26.3-61.9) & $31.5(20.6-48.5)$ & 0.014 & \begin{tabular}{|l|}
$44.5(29.0-65.9)$ \\
\end{tabular} & $30.7(19.3-42.2)$ & $<0.001$ & 45.6 (27.5-66.9) & $31.3(19.9-44.0)$ & $<0.001$ \\
\hline
\end{tabular}

${ }^{1}$ Low intake of carotenoid-rich fruits and vegetables includes the bottom tertile of dietary intake, score $<25$; high intake of carotenoid-rich fruits and vegetables includes the top tertile of dietary intake, score $>31$. $\beta$-cryptoxanthine: $\mathrm{t} 1<0.06$ and $\mathrm{t} 3>0.12 \mu$ mol/L; $\alpha$-carotene: $\mathrm{t} 1<0.08$ and $\mathrm{t} 3$ $>0.14 \mu \mathrm{mol} / \mathrm{L} ; \beta$-carotene: $\mathrm{t} 1<0.26$ and $\mathrm{t} 3>0.45 \mu \mathrm{mol} / \mathrm{L}$. 
Table 3. The distribution of demographic, physiological, behavioural and biochemical variables in the bottom (t1) and top tertiles (t3) of dietary intake of carotenoid-rich fruits and vegetables. Data are given as median (interquartile range) or number (\%).

\begin{tabular}{|c|c|c|c|}
\hline & $\begin{array}{l}\mathbf{t 1} \\
n=92\end{array}$ & $\begin{array}{l}\mathbf{t 3} \\
n=91\end{array}$ & $P$-value \\
\hline Age, years & $58(51-63)$ & $56(50-63)$ & 0.691 \\
\hline Sex, female & $31(34)$ & $65(71)$ & $<0.001$ \\
\hline Smoker & $31(34)$ & $10(11)$ & $<0.001$ \\
\hline Physically inactive & $5(5)$ & $1(1)$ & 0.096 \\
\hline $\begin{array}{l}\text { High level of physical } \\
\text { activity }\end{array}$ & $14(15)$ & $19(21)$ & 0.331 \\
\hline Low alcohol consumption & $69(75)$ & $76(84)$ & 0.310 \\
\hline $\begin{array}{l}\text { High alcohol } \\
\text { consumption, }\end{array}$ & $13(14)$ & $6(7)$ & 0.080 \\
\hline $\mathrm{BMI} \mathrm{kg/ \textrm {m } ^ { 2 }}$ & $26(23-29)$ & $26(23-30)$ & 0.757 \\
\hline $\begin{array}{l}\text { Antihypertensive } \\
\text { medication use }\end{array}$ & $13(14)$ & $8(9)$ & 0.799 \\
\hline $\begin{array}{l}\text { Systolic blood pressure, } \\
\mathrm{mmHg}\end{array}$ & $132(118-146)$ & $126(115-148)$ & 0.465 \\
\hline $\begin{array}{l}\text { Diastolic blood pressure, } \\
\mathrm{mmHg}\end{array}$ & $81(78-89)$ & $84(77-91)$ & 0.529 \\
\hline $\begin{array}{l}\text { Antihypertensive } \\
\text { medication use }\end{array}$ & $13(14)$ & $8(9)$ & 0.258 \\
\hline Total cholesterol, mmol/L & $5.45(4.90-6.00)$ & $5.40(4.90-6.00)$ & 0.680 \\
\hline HDL cholesterol, mmol/L & $1.60(1.30-1.80)$ & $1.60(1.30-1.90)$ & 0.341 \\
\hline \multicolumn{4}{|c|}{ 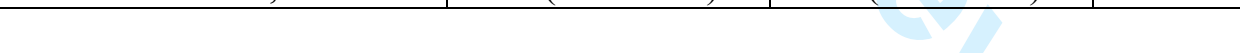 } \\
\hline Total carotenoids, $\mu \mathrm{mol} / \mathrm{L}$ & $1.06(0.73-1.44)$ & $1.53(1.10-2.00)$ & $<0.001$ \\
\hline$\beta$-cryptoxanthine, $\mu \mathrm{mol} / \mathrm{L}$ & $0.06(0.04-1.11)$ & $0.13(0.09-0.20)$ & $<0.001$ \\
\hline$\alpha$-carotene, $\mu \mathrm{mol} / \mathrm{L}$ & $0.09(0.05-0.13)$ & $0.15(0.09-0.29)$ & $<0.001$ \\
\hline$\beta$-carotene, $\mu \mathrm{mol} / \mathrm{L}$ & $0.27(0.19-0.42)$ & $0.50(0.29-0.73)$ & $<0.001$ \\
\hline Lutein, $\mu \mathrm{mol} / \mathrm{L}$ & $0.24(0.17-0.31)$ & $0.30(0.20-0.36)$ & 0.014 \\
\hline Lycopene, $\mu \mathrm{mol} / \mathrm{L}$ & $0.32(0.17-0.47)$ & $0.39(0.28-0.49)$ & 0.039 \\
\hline $\mathrm{CRP}, \mathrm{mg} / \mathrm{L}$ & $0.70(0.26-2.47)$ & $0.65(0.21-1.76)$ & 0.565 \\
\hline IL-6, pg/mL & $1.86(1.15-2.81)$ & $1.60(1.18-2.25)$ & 0.228 \\
\hline MMP-9, ng/mL & $34.5(24.9-55.1)$ & $32.1(19.2-52.2)$ & 0.188 \\
\hline
\end{tabular}

Low intake of carotenoid-rich fruits and vegetables includes the bottom tertile of dietary intake, score $<25$; high intake of carotenoid-rich fruits and vegetables includes the top tertile of dietary intake, score $>31$. 
Table 4. Relationships between regular use of vitamin supplements and levels of carotenoids and inflammatory markers. Levels are expressed as

\begin{tabular}{|l|l|l|l|}
\hline & $\begin{array}{l}\text { No use of } \\
\text { vitamin } \\
\text { supplements }\end{array}$ & $\begin{array}{l}\text { Regular use of } \\
\text { vitamin } \\
\text { supplements }\end{array}$ & P-value \\
& $n=195$ & $n=78$ & \\
\hline Total carotenoids, $\mu \mathrm{mol} / \mathrm{L}$ & $1.17(0.87-1.58)$ & $1.36(1.08-1.89)$ & 0.011 \\
\hline$\beta$-cryptoxanthine, $\mu \mathrm{mol} / \mathrm{L}$ & $0.09(0.05-0.15)$ & $0.10(0.06-0.16)$ & 0.765 \\
\hline$\alpha$-carotene, $\mu \mathrm{mol} / \mathrm{L}$ & $0.09(0.06-0.16)$ & $0.12(0.08-0.23)$ & 0.191 \\
\hline$\beta$-carotene, $\mu \mathrm{mol} / \mathrm{L}$ & $0.31(0.21-0.50)$ & $0.43(0.30-0.68)$ & 0.002 \\
\hline Lutein, $\mu \mathrm{mol} / \mathrm{L}$ & $0.26(0.19-0.33)$ & $0.28(0.20-0.34)$ & 0.804 \\
\hline Lycopene, $\mu \mathrm{mol} / \mathrm{L}$ & $0.34(0.21-0.48)$ & $0.36(0.25-0.49)$ & 0.344 \\
\hline & & & \\
\hline $\mathrm{CRP}, \mathrm{mg} / \mathrm{L}$ & $0.73(0.24-1.89)$ & $0.59(0.23-2.31)$ & 0.941 \\
\hline $\mathrm{IL}-6, \mathrm{pg} / \mathrm{mL}$ & $0.56(0.56-2.70)$ & $0.56(0.56-2.38)$ & 0.793 \\
\hline $\mathrm{MMP}-9, \mathrm{ng} / \mathrm{mL}$ & $34.5(24.2-51.9)$ & $31.7(20.2-51.9)$ & 0.498 \\
\hline
\end{tabular}

\begin{abstract}
medians (interquartile range); $P$-values based on regression adjusted for age and sex.
\end{abstract}


Table 5. Spearman rank correlation coefficients for dietary intake of carotenoid-rich fruits and vegetables (dietary carotenoids) and plasma carotenoids $(\mu \mathrm{mol} / \mathrm{L}) . * P<0.05, * * P<0.01$ and $* * * P<0.001$.

\begin{tabular}{|c|c|c|c|c|c|c|c|c|c|c|}
\hline & $\begin{array}{c}\text { Dietary } \\
\text { carotenoids }\end{array}$ & $\begin{array}{l}\text { Total } \\
\text { carotenoids }\end{array}$ & $\begin{array}{l}\beta \text {-crypto- } \\
\text { xanthine }\end{array}$ & $\alpha$-carotene & $\beta$-carotene & Lutein & Lycopene & \begin{tabular}{|l|}
$\mathrm{CRP}$, \\
$\mathrm{mg} / \mathrm{L}$
\end{tabular} & $\begin{array}{l}\text { IL-6, } \\
\text { pg/mL }\end{array}$ & $\begin{array}{l}\text { MMP-9, } \\
\text { ng/mL }\end{array}$ \\
\hline Dietary carotenoids & 1 & $0.35 * * *$ & $0.39 * * *$ & $0.35^{* * *}$ & $0.33 * * *$ & $0.13^{*}$ & 0.12 & -0.05 & -0.08 & -0.11 \\
\hline Age & -0.01 & $-0.18 * *$ & -0.02 & 0.01 & -0.01 & -0.05 & $0.42 * * *$ & $0.15^{*}$ & $0.30 * * *$ & -0.09 \\
\hline $\operatorname{Sex}$ & $0.30 * * *$ & $0.39 * * *$ & $0.36^{* * *}$ & $0.42 * * *$ & $0.43 * * *$ & $0.17 * * *$ & 0.09 & -0.05 & $-0.29 *$ & $-0.20 * * *$ \\
\hline Smoking & $0.23 * * *$ & -0.11 & $-0.15 *$ & -0.15 & $-0.13^{*}$ & -0.09 & 0.01 & -0.07 & $0.12 *$ & $0.19^{* *}$ \\
\hline Physical activity & 0.12 & 0.11 & 0.12 & 0.12 & $0.13 *$ & 0.06 & 0.01 & $-0.11^{*}$ & $-0.22^{* *}$ & -0.08 \\
\hline Alcohol consumption & -0.07 & $-0.13 *$ & -0.15 & $-0.21 * * *$ & $-0.22 * * *$ & $-0.12 *$ & 0.11 & 0.05 & 0.08 & 0.09 \\
\hline BMI, $\mathrm{kg} / \mathrm{m}^{2}$ & -0.01 & $-0.28 * * *$ & $-0.15 *$ & $-0.23 * * *$ & $-0.27 * * *$ & $-0.25 * * *$ & $-0.12 *$ & $0.38 * * *$ & $0.43 * * *$ & 0.11 \\
\hline Antihypertensive medication & -0.06 & $-0.26^{*}$ & $-0.09 *$ & $-0.18^{* *}$ & $-0.23 * * *$ & -0.11 & $-0.19 * *$ & $0.13 *$ & $0.20 * *$ & $0.16^{* *}$ \\
\hline Systolic blood pressure, $\mathrm{mmHg}$ & -0.04 & $-0.33 * * *$ & -0.13 & $-0.21 * * *$ & $-0.27 * * *$ & $-0.18^{* *}$ & $-0.27^{* *}$ & $0.16^{* *}$ & $0.24 * *$ & $0.11^{* *}$ \\
\hline Diastolic blood pressure, $\mathrm{mmHg}$ & -0.02 & $-0.28 * * *$ & -0.08 & $-0.19 * * *$ & $-0.25 * * *$ & $-0.14 *$ & $-0.23 * * *$ & $0.16^{* *}$ & $0.23 * *$ & 0.09 \\
\hline Total cholesterol, $\mathrm{mmol} / \mathrm{L}$ & -0.04 & $0.26^{* * *}$ & $0.23 * * *$ & $0.21 * * *$ & $0.20 * * *$ & $0.21 * * *$ & $0.15^{*}$ & -0.02 & -0.08 & -0.03 \\
\hline HDL cholesterol, mmol/L & 0.07 & $0.37 * * *$ & $0.28 * * *$ & $0.32 * * *$ & $0.34 * * *$ & $0.23 * * *$ & 0.10 & $-0.17 * *$ & $-0.23 *^{* *}$ & $-0.20 * * *$ \\
\hline Triglycerides, $\mathrm{mmol} / \mathrm{L}$ & -0.11 & $-0.24 * *$ & $0.17^{* *}$ & -0.18 & $-0.29 * *$ & $-0.14 *$ & -0.08 & $0.23^{* * *}$ & $0.26^{* * *}$ & $0.20^{* *}$ \\
\hline $\mathrm{CRP}, \mathrm{mg} / \mathrm{L}$ & -0.05 & $-0.24 * *$ & -0.07 & $-0.19 * * *$ & $-0.22 * * *$ & $-0.12 *$ & $-0.15 * *$ & 1 & $0.48^{* * *}$ & $0.17^{* *}$ \\
\hline IL-6, pg/mL & -0.08 & $-0.33 * * *$ & $-0.23 * * *$ & $-0.29 * * *$ & $-0.30 * * *$ & $-0.14 * *$ & $-0.22 * *$ & $0.48^{* * *}$ & 1 & $0.21 * * *$ \\
\hline MMP-9, ng/mL & -0.11 & $-0.25 * * *$ & $-0.19 * *$ & $-0.29 * * *$ & $-0.26^{* * *}$ & -0.08 & $-0.13^{*}$ & $0.17^{* * *}$ & $0.21 * * *$ & 1 \\
\hline
\end{tabular}


Table 6. Significant correlation for total carotenoids, provitamin A carotenoids and single carotenoids in plasma after full adjustment. Values are presented as regression coefficients $(\beta)$ and $P$-values are shown in parentheses.

\begin{tabular}{|c|c|c|c|c|c|c|c|}
\hline & $\begin{array}{l}\text { Total } \\
\text { carotenoids }\end{array}$ & \begin{tabular}{|l|}
$\begin{array}{l}\text { Provitamin A } \\
\text { carotenoids }\end{array}$ \\
\end{tabular} & $\begin{array}{l}\beta- \\
\text { cryptoxanthine }\end{array}$ & $\alpha$-carotene & $\beta$-carotene & Lutein & Lycopene \\
\hline Age & $-0.15(0.012)$ & --- & --- & --- & --- & --- & $-0.28(0.001)$ \\
\hline Sex & $0.18(0.003)$ & $0.16(0.011)$ & $0.13(0.045)$ & $0.18(0.003)$ & $0.17(0.008)$ & $0.14(0.026)$ & --- \\
\hline $\begin{array}{l}\text { Dietary } \\
\text { carotenoids }\end{array}$ & $0.20(<0.001)$ & $0.25(<0.001)$ & $0.17(0.006)$ & $0.27(0.001)$ & $0.18(0.002)$ & --- & --- \\
\hline BMI, $\mathrm{kg} / \mathrm{m}^{2}$ & $-0.19(<0.001)$ & $-0.20(0.001)$ & --- & $-0.19(0.001)$ & $-0.18(0.002)$ & $-0.19(0.002)$ & --- \\
\hline $\begin{array}{l}\text { Systolic blood } \\
\text { pressure, } \mathbf{m m H g}\end{array}$ & --- & --- & --- & --- & --- & --- & $0.15(0.016)$ \\
\hline $\begin{array}{l}\text { Total cholesterol, } \\
\text { mmol/L }\end{array}$ & --- & --- & --- & --- & --- & $0.17(0.003)$ & $0.13(0.031)$ \\
\hline $\begin{array}{l}\text { HDL cholesterol, } \\
\mathrm{mmol} / \mathrm{L}\end{array}$ & $0.16(0.010)$ & $0.15(0.017)$ & $0.18(0.009)$ & $0.13(0.036)$ & $0.13(0.042)$ & --- & --- \\
\hline MMP-9, ng/mL & $-0.13(0.018)$ & $-0.12(0.028)$ & $-0.12(0.044)$ & $-0.13(0.020)$ & $-0.11(0.059)$ & --- & --- \\
\hline
\end{tabular}

